\title{
Implant Overloading Considerations for Implant Assisted Overdentures (IAOD)
}

\author{
Mohamed A EI Maroush ${ }^{\text {a }}$, Suleiman M Esayah ${ }^{\text {b }}$, Osama Mohammed Askar ${ }^{c}$ \\ ${ }^{a}$ Associate Professor at Prosthodontics Department, Faculty of Dentistry, Tripoli University, Libya. \\ ${ }^{\mathrm{b}}$ Assistant lecturer at prosthodontics Department, Faculty of Dentistry, Sabratha University, Libya \\ ${ }^{c}$ Assistant Professor at Prosthodontics Department, Faculty of Dentistry, Mansoura University, Egypt.
}

\begin{abstract}
The loss of retention and stability are considered the most common prosthetic problems that face prosthodontics in complete denture patients especially with continued residual ridge resorption, which increased the number of patients' seeking improvement of the retention and stability in order to use their dentures. The implant supported overdenture is considered the best option of treatment to solve these problems. Implants may be subjected to occlusal overloading during function which will negatively affect the prognosis of implant osseintegration. This encouraged us to review the literature concerning the factors affecting implant assisted overdentures (IAOD) overloading and how to control them to the benefit and comfort of the patient as well as longevity of the prosthetic.
\end{abstract}

Keywords: implant overdenture, occusal overload, factors affecting implant loading,

\section{Introduction:}

The introduction of osseointegrated implants into dentistry has provided a new alternative for the rehabilitation of edentulous patients. Implant supported overdentures can provide an effective treatment modality for patients with persistent problems related to retention and stability of their conventional prostheses. ${ }^{1-3}$ As patient functions with an implant supported overdenture, overloading or stresses are transmitted to the implant interfacial alveolar bone. If these stresses exceed the physiologic limit of alveolar bone, resorption of alveolar bone occures ${ }^{3}$. Many factors should be considered during the construction of implant assisted overdenture prosthesis such as occlusion, attachment system used, cantilever length, type of material used, ideal implant positioning and distribution, impression technique, adequate prosthesis construction and passivity. ${ }^{4}$ Also, other patient related factors play an important role in implant overloading such as: poor bone quality and quantity, systemic condition of the patient's musculature and strength of their biting force, condition and nature of opposing occlusal surface and patients with parafunctional habits. ${ }^{5}$ This article is a review of these factors.

Factors that control (prognosis of) implant assisted overdenture (IAOD) overloading?

Prosthesis related factors

Many prosthetic factors and clinical related scenarios that should be considered during the construction and planning of IAOD, which may be responsible for implants overloading such as:

\section{Implant overdenture attachment system selected.}

Tabata et al. ${ }^{67,8}$ found that, splinted bar-clip attachment systems can reduce the amount of stresses and strains on the peri-implant bony tissues compared to solitary non splinted attachments in stress strain analysis study due to primary splinting effect and load sharing. While bar unit attachments which do not allow any movement of the overdenture during function and used with limited interocclusal space scenarios transfer all the load onto the implants. On the other hand, resilient attachment might cause posterior 
mandibular resorption with the vertical movement of the denture in case of two implants assisted mandibular overdentures due to allowing load sharing by the posterior ridge area. ${ }^{9}$ Also, The stud resilient attachments permit some tissue ward vertical and rotational movements, thus protecting the underlying abutments or implants against overload ${ }^{9}$. Gross (2008), recommended to reduce the height of the attachment as much as possible in order to reduce any horizontal forces ${ }^{10}$.

A Hader bar, which is round in cross section is subjected to the most stress concentration and hence subject to fracture and subsequent failure. ${ }^{11}$ Also, large bar span lead to excessive flexure of the round bar which leads to screw loosening, casting fracture, and stress concentrations around the implants. ${ }^{12}$

Cantilevers are a Class-I lever, which double the amount of stress on the abutment closest to the cantilever. Cantilevers also add to noxious stresses (force on a cantilever is compressive, while force on a distant abutment is tensile). ${ }^{10}$ The amount of force that falls on the most distal implant is directly proportional to the length of cantilever arm. Himmolova et al, reported that the use of long distal cantilever bar extension for mucosal implant supported overdenture caused favourable load distribution to the alveolar ridge but on the expense of implant supported structures. The length of cantilever extension is strongly affected by the number, distribution, length of implants and quality of alveolar bone ${ }^{13}$. The All-on-Four protocol requires the placement of four interforaminal implants, with the distal implants tilted distally by 30 degrees to achieve a more favourable anteroposterior distribution of implants, thereby minimizing cantilever extensions that could jeopardize osseointegration of the distal implants. The following cantilever lengths are recommended: Maxillary anteriors-10 mm; maxillary posteriors- $15 \mathrm{~mm}$; mandibular posteriors- $20 \mathrm{~mm}$. In addition, a gradient type of occlusal contact force along the length of cantilever may be beneficial.

\section{The fitting of framework}

Poor fitting of prosthesis on implants or loss of passivity is responsible for transfering unwelcome stresses to the bone/implant interface, which could induce a loss of osseointegration. ${ }^{18}$ The implant supported frame work is considered to be passive when simultaneous and even contact between the whole inner surface of frame work with all implant abutments without inducing any strain on the supporting implant components and surrounding bone structure in the absence of occlusal loads. ${ }^{19}$ Which depend on accuracy of impression technique, materials and technique used in the construction of framework.

\section{The material of framework}

During function, occlusal forces are transmitted to the prosthesis, implant, and the bone around the implant, respectively which create stresses that lead to bone resorption around the implant and loss of implants This phenomenon is referred to as stress shielding, and it may be one of the important causes of long term failure of dental implants. ${ }^{20}$ The materials selected in the construction of such big restorations should be light in weight with high mechanical properties, so restorations formed from ceramic fused to metal, Titanium or zirconia full arch restorations are heavy in weight and have high modulus of elasticity greater than that of compact bone $(15 \mathrm{GPa})$ and titanium $(110 \mathrm{GPa})$ and zirconia $(210 \mathrm{GPa})^{21}$

The framework material which has the lower modulus of elasticity showed a more even distribution of stress in the prosthetic components and the bone. ${ }^{22}$ The new trend now is to use metal free that can be used in the construction of large implant supported fixed or hybrid prostheses which are light in weight, radio lucent, biocompatible, degradation-resistant, have physical properties close to bone, have damping action and can accept repair and modification easily like: (1) fiber reinforced composites like: Trinia (Bicon LLC) ${ }^{23}$ and TriLor $\mathrm{Arch}^{24}$. (2) synthetic thermoplastic semi crystalline aromatic polymer of Poly-aryl-ether-ketones (PAEK) like poly-ether-ether-ketone (PEEK) Bio HPP ${ }^{21}$ and recently poly-ether-ketone-ketone (PEKK ) Pekkton ${ }^{\circledR i v o r y}$ which has a similar compressive strength $(246 \mathrm{MPa})$ to that of bone and tooth dentine $(297$ $\mathrm{MPa})^{25}$, shock absorption, and it is the material of choice for the construction of the framework for implant supported full arch prosthesis because of its light weight and compatibility with different veneering materials, in addition it can be milled or heat-pressed, and it was used successfully in implant overdenture attachments. $^{25-29}$

\section{Direction of occlusal force and implants angulation}

The implants should be positioned in order to allow occlusal forces to be with the long axis of implants ${ }^{30}$, these forces are transferred through implants to the surrounding bone as stresses that should not exceed the physiologic limit tolerated by surrounding bone. ${ }^{31}$ Non axial forces have a negative effect more than the 
axial forces on implant systems which was proved by In vitro and in vivo studies. ${ }^{32}$ According to Glossary of oral and maxillofacial implants occlusal overload is 'the application of occlusal loading, through function or parafunction, in excess of what the prosthesis, implant component or osseointegrated interface is capable of withstanding without structural or biologic damage'. ${ }^{33}$ The maintenance of the bone/implant interface is particularly dependent on the control of biomechanical loads ${ }^{34}$

\section{Premature contacts or occlusal interferences}

Chapman, $\boldsymbol{R}^{35}$. suggested some recommendations in order to reduce occlusal over load on dental implants supported restorations including: (1) simulations bilateral contact, (2) no premature contacts in centric occlusion and retruded contact position, (3) lateral excursive movements should be smooth, even and without any interferences, (4) presence of anterior guidance, (5) equal distribution of occlusal forces and contacts.

Premature contacts and occlusal interference are important factors that should be monitored in the IAODs as they can create non axial forces that may cause occlusal overloading and irreversible structural and biological damage ${ }^{36}$. Prematurities should be eliminated during maximum intercuspation and centric relation. ${ }^{17,37}$ light occlusal contacts, occlusal forces should be distributed on adjacent natural teeth and the plane of occlusion should be followed. ${ }^{38}$ Occlusal contacts should be infraoccluded by $(100 \mu \mathrm{m})$ on the teeth over the cantilever portion of the prosthesis ${ }^{14}$.

\section{Reduction of the occlusal table width}

The wider the occlusal table, the greater the force developed to penetrate a bolus of food. Furthermore, several modifications, including minimum cantilever, narrow occlusal table, flat cusp inclination, 1 to 1.5 $\mathrm{mm}$ of freedom in centric relation, no contact with opposite dentition during excursion It was found that narrowing the occlusal table by $30 \%$ significantly reduces the magnitude of lateral forces by $48 \%{ }^{39}$

\section{Patient related factors:}

\section{Parafunctional habits (Bruxism and clenching habits)}

Para-functional activities and improper occlusal designs have negatively affected the prognosis of endosseous implants and may cause implant bone loss/failure, implant fractures, and prosthesis failures, due to the generation of excessive lateral forces, especially that dental implants lack the sufficient resistance to lateral forces. ${ }^{40,41}$

\section{Quality of bone and time of loading:}

Alveolar bone quality plays an important role in the success of dental implants and on the magnitude of load that can be tolerated by implants which is transferred through implant supported prosthesis especially in areas that have poor bone quality like posterior areas of maxilla which in turn may be responsible for the long-term failure of dental implants if the prosthesis are not well designed. ${ }^{13,42}$

Cases that have type IV bone quality are best to be delayed loaded after a period of 5 to 7 months ${ }^{43}$ or we can follow the progressive loading protocol which proved to improve the crestal bone quality ${ }^{44}$. In these cases increased load on peri-implant tissue can be compensated by increasing augmentation if necessary; increasing the number of implants; or splinting implant prosthesis in order to distribute force and decrease load per implant ${ }^{17,45}$.

\section{Condition of opposing occlusal surface}

Quirynen $\mathrm{M}$ et al. ${ }^{46}$ have recommended a bilateral lingualized balanced occlusal scheme when rehabilitating complete edentulous mandible with dental implants. In case of the fully edentulous maxilla, whether the mandibular rehabilitation is done on an overdenture supported on two implants or on a mucosalimplant-supported overdenture (four implants with a bar attachment). ${ }^{17}$ Also, in conditions where a Kennedy class I or II partially edentulous condition is present in the maxillary arch and mandibular mucosa-implant supported (four implants with a bar attachment) or an implant-supported prosthesis is planned for the mandibular arch, also balanced occlusion is recommended.

A group function or mutually protected occlusion is advised in case of maxillary Kennedy class I RPD opposed by a total implant supported fixed denture prosthesis (FDP). While in cases that have maxillary Kennedy class III or IV opposed by implant-supported prosthesis, group function or mutually protected 
occlusion is recommend_ed. Lastly, in case of the fully dentate maxilla and implant-supported prosthesis, group function or mutually protected occlusion is recommended. ${ }^{17}$

\section{Sequla of implant overload:}

The biomechanical load on the dental implants has affected the outcome of implant treatment. ${ }^{47}$ Mechanical stresses in peri-implant bone, induced by occlusal loads transmitted to these implants, is known to affect bone homeostasis. ${ }^{48}$ The occlusal overload can cause mechanical complications on dental implants and implant prostheses such as screw loosening and/or fracture, prosthesis fracture, and implant fracture, eventually leading to a compromised implant longevity. ${ }^{49}$ Also, Occlusal overload is one of the main causes of Biological complication such as peri-implant bone loss and implant/implant prosthesis failure. The stress is thus transmitted from the prostheses to the implant-bone interface at the crestal level, leading to loss of osseointegration and/or crestal bone loss. ${ }^{50}$

\section{Conclusion:}

Within the limitations of this study, it may be concluded that: the implant supported overdenture is a better treatment for edenuolos patient. This type of treatment is subjected to (higher or Lower)stress concentrations due to occulsal overload. which leads to abnormally high stresses that are transmitted to the supporting tissues causing pressure necrosis and subsequently failure of the implant overdenture.

\section{References:}

1. Adell R, Lekholm U, Rockler B, Brånemark P-IJIjoos. A 15-year study of osseointegrated implants in the treatment of the edentulous jaw. 1981; 10: 387-416.

2. Celik G, Uludag BJTJopd. Photoelastic stress analysis of various retention mechanisms on 3implant-retained mandibular overdentures. 2007; 97: 229-235.

3. Mericske-Stern RJTJopd. Treatment outcomes with implant-supported overdentures: clinical considerations. 1998; 79: 66-73.

4. Zurdo J, Romao C, Wennström JLJCoir. Survival and complication rates of implant-supported fixed partial dentures with cantilevers: a systematic review. 2009; 20: 59-66.

5. Jovanovic SAJAidr. Peri-implant tissue response to pathological insults. 1999; 13: 82-86.

6. van Kampen F, Cune M, van der Bilt A, Bosman F. Retention and postinsertion maintenance of barclip, ball and magnet attachments in mandibular implant overdenture treatment: an in vivo comparison after 3 months of function. Clin Oral Implants Res 2003; 14: 720-726.

7. Vafaei F, Khoshhal M, Bayat-Movahed S, Ahangary AH, Firooz F, Izady A, Rakhshan V. Comparative stress distribution of implant-retained mandibular ball-supported and bar-supported overlay dentures: a finite element analysis. J Oral Implantol 2011; 37: 421-429.

8. Tabata LF, Assunção WG, Barão VAR, Gomes EA, Delben JA, de Sousa EAC, Rocha EPJJoCS. Comparison of single-standing or connected implants on stress distribution in bone of mandibular overdentures: a two-dimensional finite element analysis. 2010; 21: 696-702.

9. Brewer AA, Fenton AH. The overdenture. Dent Clin North Am 1973; 17: 723-746.

10. Gross MD. Occlusion in implant dentistry. A review of the literature of prosthetic determinants and current concepts. Aust Dent J 2008; 53 Suppl 1: S60-68.

11. Satheesh Kumar P, Satheesh KK, John J, Patil G, Patel RJISRN. Force transfer and stress distribution in an implant-supported overdenture retained with a hader bar attachment: a finite element analysis. 2013; 2013.

12. Trakas T, Michalakis K, Kang K, Hirayama HJId. Attachment systems for implant retained overdentures: a literature review. 2006; 15: 24-34.

13. AlOthman Y, AlLubli HJEDS. Occlusal Considerations in Dental Implantology. 2019; 18: 18721883.

14. Taylor TD. Fixed implant rehabilitation for the edentulous maxilla. Int J Oral Maxillofac Implants 1991; 6: 329-337. 
15. Falk H, Laurell L, Lundgren D. Occlusal interferences and cantilever joint stress in implantsupported prostheses occluding with complete dentures. Int J Oral Maxillofac Implants 1990; 5: 7077.

16. Duyck J, Van Oosterwyck H, Vander Sloten J, De Cooman M, Puers R, Naert I. Magnitude and distribution of occlusal forces on oral implants supporting fixed prostheses: an in vivo study. Clin Oral Implants Res 2000; 11: 465-475.

17. Verma M, Nanda A, Sood AJJotICDRO. Principles of occlusion in implant dentistry. 2015; 7: 27.

18. Kunavisarut C, Lang LA, Stoner BR, Felton DA. Finite element analysis on dental implantsupported prostheses without passive fit. J Prosthodont 2002; 11: 30-40.

19. Sahin S, Cehreli MC. The significance of passive framework fit in implant prosthodontics: current status. Implant Dent 2001; 10: 85-92.

20. Pesqueira AA, Goiato MC, Filho HG, Monteiro DR, Santos DM, Haddad MF, Pellizzer EP. Use of stress analysis methods to evaluate the biomechanics of oral rehabilitation with implants. J Oral Implantol 2014; 40: 217-228.

21. Bathala L, Majeti V, Rachuri N, Singh N, Gedela S. The Role of Polyether Ether Ketone (Peek) in Dentistry - A Review. J Med Life 2019; 12: 5-9.

22. Evtimovska E, Masri R, Driscoll CF, Romberg E. The change in retentive values of locator attachments and hader clips over time. J Prosthodont 2009; 18: 479-483.

23. Passaretti A, Petroni G, Miracolo G, Savoia V, Perpetuini A, Cicconetti A. Metal free, full arch, fixed prosthesis for edentulous mandible rehabilitation on four implants. J Prosthodont Res 2018; 62: 264-267.

24. Gumbau G, López A, Diago M, Diagoa M. All-on-4 with tapered neck implants and a hybrid prosthesis with a fiberglassreinforced structure. Journal of Oral Science \& Rehabilitation 2019; 5.

25. Kotthaus M, Hasan I, Keilig L, Gruner M, Bourauel C, Stark H. Investigation of the retention forces of secondary telescopic crowns made from Pekkton(R) ivory in combination with primary crowns made from four different dental alloys: an in vitro study. Biomed Tech (Berl) 2019; 64: 555-562.

26. Dawson JH, Hyde B, Hurst M, Harris BT, Lin WS. Polyetherketoneketone (PEKK), a framework material for complete fixed and removable dental prostheses: A clinical report. J Prosthet Dent 2018; 119: $867-872$.

27. Oh KC, Park JH, Lee JH, Moon HS. Treatment of a mandibular discontinuity defect by using a fibula free flap and an implant-supported fixed complete denture fabricated with a PEKK framework: A clinical report. J Prosthet Dent 2018; 119: 1021-1024.

28. Choi JW, Yun BH, Jeong CM, Huh JB. Retentive Properties of Two Stud Attachments with Polyetherketoneketone or Nylon Insert in Mandibular Implant Overdentures. Int J Oral Maxillofac Implants 2018; 33: 1079-1088.

29. Bae SY, Park JY, Jeong ID, Kim HY, Kim JH, Kim WC. Three-dimensional analysis of marginal and internal fit of copings fabricated with polyetherketoneketone (PEKK) and zirconia. $J$ Prosthodont Res 2017; 61: 106-112.

30. Brunski JB. Biomechanical considerations in dental implant design. Int J Oral Implantol 1988; 5: 3134.

31. Satheesh Kumar P, Satheesh KK, John J, Patil G, Patel R. Force transfer and stress distribution in an implant-supported overdenture retained with a hader bar attachment: a finite element analysis. ISRN Dent 2013; 2013: 369147.

32. Nishioka RS, de Vasconcellos LG, Joias RP, Rode Sde M. Load-application devices: a comparative strain gauge analysis. Braz Dent J 2015; 26: 258-262.

33. Broggini N, Cirelli J. Glossary of oral and maxillofacial implants. Quintessence

34. Isidor F. Influence of forces on peri-implant bone. Clin Oral Implants Res 2006; 17 Suppl 2: 8-18.

35. Chapman RJ. Principles of occlusion for implant prostheses: guidelines for position, timing, and force of occlusal contacts. Quintessence Int 1989; 20: 473-480.

36. Laney WR. Glossary of Oral and Maxillofacial Implants. Int J Oral Maxillofac Implants 2017; 32 : Gi-G200.

37. Miyata T, Kobayashi Y, Araki H, Ohto T, Shin K. The influence of controlled occlusal overload on peri-implant tissue. part 4: a histologic study in monkeys. Int J Oral Maxillofac Implants 2002; 17: 384-390. 
38. Lundgren D, Laurell L. Biomechanical aspects of fixed bridgework supported by natural teeth and endosseous implants. Periodontol 2000 1994; 4: 23-40.

39. Morneburg TR, Proschel PA. In vivo forces on implants influenced by occlusal scheme and food consistency. Int J Prosthodont 2003; 16: 481-486.

40. Conrad HJ, Schulte JK, Vallee MC. Fractures related to occlusal overload with single posterior implants: a clinical report. J Prosthet Dent 2008; 99: 251-256.

41. Rangert B, Krogh PH, Langer B, Van Roekel N. Bending overload and implant fracture: a retrospective clinical analysis. Int J Oral Maxillofac Implants 1995; 10: 326-334.

42. Hutton JE, Heath MR, Chai JY, Harnett J, Jemt T, Johns RB, McKenna S, McNamara DC, van Steenberghe D, Taylor R, et al. Factors related to success and failure rates at 3-year follow-up in a multicenter study of overdentures supported by Branemark implants. Int J Oral Maxillofac Implants 1995; 10: 33-42.

43. Misch CE. Endosteal implants for posterior single tooth replacement: alternatives, indications, contraindications, and limitations. J Oral Implantol 1999; 25: 80-94.

44. Appleton RS, Nummikoski PV, Pigno MA, Cronin RJ, Chung KHJCoir. A radiographic assessment of progressive loading on bone around single osseointegrated implants in the posterior maxilla. 2005; 16: 161-167.

45. Rangert B, Krogh PH, Langer B, Van Roekel NJljoo, implants $\mathrm{m}$. Bending overload and implant fracture: a retrospective clinical analysis. 1995; 10.

46. Quirynen M, Naert I, Van Steenberghe DJCoir. Fixture design and overload influence marginal bone loss and future success in the Brånemark ${ }^{\circledR}$ system. 1992; 3: 104-111.

47. Baggi L, Cappelloni I, Di Girolamo M, Maceri F, Vairo G. The influence of implant diameter and length on stress distribution of osseointegrated implants related to crestal bone geometry: a threedimensional finite element analysis. J Prosthet Dent 2008; 100: 422-431.

48. Pavlin D, Gluhak-Heinrich JJCRiOB, Medicine. Effect of mechanical loading on periodontal cells. 2001; 12: 414-424.

49. Schwarz MS. Mechanical complications of dental implants. Clin Oral Implants Res 2000; 11 Suppl 1: 156-158.

50. Quirynen M, Naert I, van Steenberghe D, Nys L. A study of 589 consecutive implants supporting complete fixed prostheses. Part I: Periodontal aspects. J Prosthet Dent 1992; 68: 655-663. 